\title{
PReserch Square \\ Human-Pathogenic Isolations in Stagnant Water During Peruvian El Niño-Costero Phenomenon
}

Jeel Jr Moya-Salazar

Hospital Nacional Docente Madre Niño San Bartolome https://orcid.org/0000-0002-7357-4940

Hans Contreras-Pulache ( $\nabla$ hans.contreras@uwiener.edu.pe )

Universidad Norbert Wiener

\section{Research note}

Keywords: Water-borne disease, Diarrhea, Climate change, Floods, El Nino-Southern Oscillation, Water Microbiology

Posted Date: July 2nd, 2020

DOl: https://doi.org/10.21203/rs.3.rs-36885/v1

License: (1) This work is licensed under a Creative Commons Attribution 4.0 International License. Read Full License 


\section{Abstract}

Objective: To evaluate the microbiological quality of stagnant waters in Lambayeque region, Peru during the lockdown caused by El Niño-costero phenomenon.

Results: We conducted a descriptive study in four Lambayeque's districts: (Chiclayo's downtown, Mocupe, San José, and Pimentel). Two simultaneous samples were taken from each evaluation districts and were transported to the Hospital San Bartolome in Lima Peru for their entire microbiological analysis. We isolate of human-pathogenic microorganisms (Trichuris trichiura, Entamoeba histolytica, Staphylococcus aureus, and Salmonella typhi) that showed patterns of r-esistance to conventional first-line antimicrobials (penicillin, nalidixic acid, nitrofurantoin, and chloramphenicol). Likewise, we showed evidence of microorganisms related to the sampling site (district) and with the degree of affectation by the phenomenon $(p<0.05)$. Our results suggests that the stagnant waters of four districts of Lambayeque presented Human-pathogenic parasites and bacteria of high-medical importance by the sudden changes in the climate through El Niño-costero phenomenon

\section{Introduction}

Several countries are extremely susceptible to climate change, a phenomenon that not only has been causing irretrievable changes in our biodiversity but is changing the patterns of diseases affecting human health [1]. The greatest consequences for infectious diseases caused by climate change are the rapid modifications in their transmission nowadays [2].

Asia-Pacific and Africa countries are affected by El Niño phenomenon that causes extreme events (persistent heavy rain, floods, etc.) which results in a large number of victims, poverty, inequality, and diseases [3]. In 2017, Peru was affected by intense rains, floods, and high-daily dry temperatures (100.4 \pm $\left.4{ }^{\circ} \mathrm{F}\right)$, which has shaped an unusual phenomenon called El Niño-costero, similar to El Niño phenomenon but located in the coasts of Ecuador, Colombia, and Peru [4].

This phenomenon affected more than two million people and had a large socioeconomic impact in Peru, principally in the northern coastal region (Lambayeque region). In Chiclayo, capital of the Lambayeque region, > 28000 people were affected by the El Niño-costero phenomenon (ENCP) with losses of infrastructure, agriculture, social and health problems (mainly respiratory diseases and vector and waterborne disease) [5].

As this phenomenon caused a stagnation of water, stagnant waters were used as a source of human consumption for several months. The health consequences of the stagnation of water have not been evaluated during ENCP, but in several previous studies the potential risk of these for human health is underlined $[6,7]$.

We evaluate the microbiological quality of stagnant waters in Lambayeque region, during the ENCP, focused on the isolation of microorganisms of medical importance that represent a risk for the 


\section{Main Text}

\section{Geographic location}

This descriptive study was carried out in four main districts of Lambayeque region ( 27 meters-above-sealevel,) northwest of Peru (Fig. 1). Chiclayo had 843445 inhabitants and is divided into eight urban districts.

The Chiclayo's downtown has a hospital (Hospital Regional Docente Las Mercedes -Level II), 14 health centers and 6 health stands, all belonging to the Ministry of Health of Peru. Moreover, the city has a Hospital Level I (Naylamp Hospital) and a Level IV (Almanzor Aguinaga Asenjo Hospital) belonging to Social Security. The ENCP affected this region between January to May 2017, with February being the most affected (an approximate of 5363 collapsed houses, and 4595 families affected).

\section{Samples}

The sampling was performed in the four Lambayque's districts: two zones of Mocupe district (north of Chiclayo, semi-urban district of Lagunas, $>10$ thousand inhabitants), the metropolitan area of Chiclayo (downtown, > 550 thousand inhabitants), San José district (west of Chiclayo, > 15 thousand inhabitants), and Pimentel district (west of Chiclayo, $>35$ thousand inhabitants). These districts were the most affected by the phenomena keeping the waters stagnant for $\geq 4$ weeks. We have collected randomly $4 \pm$ $1 \mathrm{ml}$ of samples of stagnant water from these districts during the afternoon, after the rain, with protection barriers.

Two simultaneous samples were taken from each evaluation area in sterile plastic bottles of $10 \mathrm{ml}$. The samples were stored under refrigeration $\left(2 \pm 1^{\circ} \mathrm{C}\right.$ ) for $\leq 5$ hours until transport ( 8 hours) to the Hospital Nacional Docente Madre Niño San Bartolome (HONADOMANI SB) in Lima. To avoid errors in this phase, part of the sample was transported with the BBL Culture Swab ${ }^{\text {TM }}$ Plus collection and transport system (BD, Le Pont de Claix, France).

\section{Microbiological analysis}

All the samples were processed once they arrived at HONADOMANI SB. The isolation were performed following bacteriological methods in the stool-culture area in $5 \%$ blood-sheep agar with membrane filter grid GN-6 Metricel® $0.45 \mu \mathrm{m}, 47$ mm (PALL, NY, USA); in Karmali agar, McConkey agar, SalmonellaShigella agar, Thiosulfate-Citrate-Bile-Sucrose agar, Sorbitol-MacConkey agar, and Mannitol salt agar (all from Merck, Darmstadt, Germany). Likewise, we used cetrimide agar (Britania, CABA, Argentina) and Saboraund-dextrose agar (Oxoid, Hampshire, England).

For identification of bacteria the biochemical analysis was performed with the system Vitek ${ }^{2}$ Compact (BioMérieux, Marcy-l'Étoile, France), and antibiogram was by disc diffusion with Breakpoints from CLSI 
M100S [8]. The sample was referred to the parasitology area for identification of human-pathogenic parasites following a previous concentration methods [9], included bright-field microscopy and rapid test (rbiopharm, Darmstadt, Germany) for most frequently parasite as amoebas and helminths. Also, we conducted a determination of Rotavirus (Rota-Strip, Coris Bioconcept, Gembloux, Belgium). The microbial enumeration techniques employed in this research were the Most Probable Number (MPN) techniques following the previous protocol [10]. Opportunistic bacteria of non-fecal origin were not evaluated.

\section{Statistical analysis}

The Pearson analysis was performed to show the difference between the samples analyzed. The MPN was estimated by the number of positive tubes for coliforms in each dilution. A $p$-value $<0.05$ was considered statistically significant. The statistical analysis was done by IBM SPSS v21.0 (Armonk, USA).

\section{Results}

Pimentel's district was the most affected and Chiclayo was the least affected. Ten samples [four (40\%) samples from Mocupe district, and two samples (20\%) from San José, Chiclayo, and Pimentel each] were included in this study. Of the 20 analyzes ( 10 with the transport-medium system and ten directly from water samples), in 6 (30\%) and $2(10 \%)$ were isolated Enterobacteria and Staphylococcus aureus (both $\geq$ 100000 UFC). E. coli were not isolated and rotavirus was not evident in stagnant water samples. Differences were found between the sampling sites, and isolates of pathogenic bacteria $(p=0.001)$.

We reported $S$. beta-lactam (penicillin) aureus resistant and sensitivity to methicillin (SAMS), also Salmonella typhi were resistant to nitrofurans (nitrofurantoin), anfenicoles (chloramphenicol), and quinolones (nalidixic acid).

The highest faecal coliform count was $5.1 \times 10^{6}$ microorganisms $/ 100 \mathrm{ml}$ obtained in Pimentel district, and the average faecal coliform count was $4.4 \pm 0.7 \times 10^{6}$ microorganisms $/ 100 \mathrm{ml}$ in all the sampling sites. The MPN counts ranged between $4.9 \times 10^{4}$ microorganisms $/ 100 \mathrm{ml}$ (lowest) recorded at Chiclayo district and $1.9 \times 10^{8}$ microorganisms $/ 100 \mathrm{ml}$ (highest) detected at Pimentel district. Both faecal coliform count and MNP exceeded the acceptable limits.

As for parasitological findings, only in the Pimentel district was found eggs of Trichuris trichiura (human whipworm) and two trophozoites of the protozoa Entamoeba histolytic (Fig. 2).

The Pimentel district showed the greatest bacterial and parasitic contamination (50\%). A significant positive correlation was found between the parasitological findings and the place of origin of the samples $(p=0.002)$. No difference was found in the microbiological analysis between samples $(p=$ $0.742)$, nor between the findings in the transport-medium system and from water samples $(p=0.001)$.

We demonstrated for the first time the isolation of pathogenic microorganisms of high medical importance that showed patterns of resistance to conventional first-line antimicrobials. Our results also 
showed evidence of parasites related to the sampling site (district) and the level of effects by the ENCP at Lambayeque, Peru.

The ENCP caused that most of water (potable and free) contains impurities and organic remains, polluting the large numbers of water reserves, and shortages and/or limiting access to clean water for human consumption in the affected districts of Lambayeque. This leads the phenomena-affected communities to use and consume water from other sources (such as stagnant water) under different rudimentary water-treatment systems. Greater faecal coliform $\left(5.1 \times 10^{6}\right.$ microorganisms $\left./ 100 \mathrm{ml}\right)$ and the MPN $\left(1.9 \times 10^{8}\right.$ microorganisms $\left./ 100 \mathrm{ml}\right)$ were indicative of the low quality of stagnant water and the high risk to which these communities are exposed. Our findings agree with previous reports on MPN in waters in developing countries with high frequency of climatic phenomena [11, 12].

Faecal contamination of these stagnant waters may be responsible for health-associated problems, like the acute diarrheal disease (220 425 cases) mainly in children [13]. Our data agree and showed coliforms, Enterobacteria (S. typhi cause of Typhoid fever, $P$. shigelloides related to diarrheal and gastroenteritis) and parasites (T. trichiura and E. hystolitica cause of persists diarrhea) highly dangerous for human health.

The adaptation of these pathogens in stagnant waters composes a risk mainly for children (Fig. 2). Several evaluations have shown microbiological contamination in drinking water worldwide, highlighting high frequency and risk in low-income countries $[14,15]$. Other findings only in the district of Pimentel evidenced protozoa and helminths on these stagnant waters. Under the precarious conditions caused by the ENCP the regional level four major hospitals were declared in red alert [16], and the other health centers showed flaws in basic services (due to flooding, access obstruction (Fig. 2), lack of personnel, etc.).

This study suggests that the stagnant waters of four districts of Lambayeque presented Humanpathogenic parasites and bacteria of high-medical importance that places people at high risk of infection and development of acute diarrheal disease.

\section{Limitations}

The study results should be interpreted under the following limitations. First, no molecular tests were performed to confirm the presence of parasites and bacteria, and to evaluate antibiotic resistance genes. Second, due to the state of emergency by ENCP, no more affected areas could be analyzed. This also prevented the higher volume of water from being analyzed according to previous studies [17]. Finally, the stagnant waters were not monitored for weeks, since it is possible that there are changes in the amount of parasites and bacteria present.

\section{Abbreviations}

ENCP: El Niño-costero phenomenon 


\section{Declarations}

\section{Ethics approval and consent to participate: none}

Funding: Self-funding by the authors

Author's contributions: JMS: study conception, study design, sample collection and analysis, data analysis, article writing, approval of the final version. HCP: study design, data analysis, article writing, final version approval

Availability of data and material: none

Competing interests: The authors declare that they have no competing interests.

Consent for publication: Not applicable.

Acknowledgements: We acknowledge support from Sandy Diaz during data sampling and analysis.

\section{References}

1. Metcalf CJE, Walter KS, Wesolowski A, Buckee CO, Shevliakova E, Tatem AJ, et al. Identifying climate drivers of infectious disease dynamics: recent advances and challenges ahead. Proc R Soc B. 2017; 284: 20170901.

2. Greenspan SE, Bower DS, Roznik EA, Pike DA, Marantelli G, Alford RA, et al. Infection increases vulnerability to climate change via effects on host thermal tolerance. Sci Rep 2017; 7:9349.

3. Glantz MH. Currents of Change: Impacts of El Niño and La Niña on Climate and Society. Cambridge: Cambridge University Press; 2001.

4. Chinchay M. El Niño Costero es un desafío para los científicos del Perú y del mundo. Available from: http://larepublica.pe/sociedad/1024258-el-nino-costero-es-un-desafio-para-los-cientificos-del-peru-ydel-mundo

5. World Health Organization. El Niño and Health. Global overview 2016. Geneva: WHO Humanitarian Health Action; 2016.

6. Aghajani A, Dabirzadeh M, Maroufi Y, Hooshyar H. Identification of Acanthamoeba Genotypes in Pools and Stagnant Water in Ponds in Sistan Region in Southeast Iran. Turkiye Parazitol Derg. 2016; 40(3):132-136.

7. Chen L, Jia RB, Li L. Bacterial community of iron tubercles from a drinking water distribution system and its occurrence in stagnant tap water. Environ Sci Process Impacts. 2013; 15(7):1332-40.

8. Clinical and Laboratory Standards Institute (CLSI). Performance Standards for Antimicrobial Susceptibility Testing. 26th ed. CLSI supplement M100S. Clinical and Laboratory Standards Institute, 950 West Valley Road, Suite 2500, Wayne, Pennsylvania 19087 USA, 2016. 
9. Zarlenga DS, Trout JM. Concentering, purifying and detecting waterbone parasites. Vet Parasitol. 2004; 126: 195-217.

10. Leuta QA. Microbial Pollutants in Stagnant Water in RR section, Khayelitsha, Western Cape, South Africa. [Thesis] Cape town: Faculty of Applied Science, Cape Peninsula University of Technology; 2015.

11. Venegas-Pérez ME, Ramírez-López EM, López-Santos A, Magaña-Rueda VO, Avelar-González JF. The impact of phenomena El Niño and La Niña and other environmental factors on episodes of acute diarrhoea disease in the population of Aguascalientes, Mexico: a case study. Adv Geosci. 2016; 42 : 15-21.

12. Emiliani F. Effects of hydroclimatic anomalies on bacteriological quality of the Middle Paraná River (Santa Fe, Argentina). Rev Arg Microbiol. 2004; 36:193-201.

13. Silva CJH, Hernández CJG. Impact of the "El Niño Costero" phenomenon on the Peruvian population's health in 2017. Medwave 2017;17(8):e7052.

14. van der Wielen PWJJ, van der Kooij D. Nontuberculous Mycobacteria, Fungi, and Opportunistic Pathogens in unchlorinated Drinking Water in the Netherlands. Appl Enviromen Microbiol. 2013; 79(3): 825-834.

15. Ashbolt NJ. Microbial contamination of drinking water and disease outcomes in developing regions. Toxicology. 2004; 198: 229-238

16. Vega Y. Más de 16 mil afectados dejan Iluvias en Lambayeque. Available from : http://larepublica.pe/impresa/sociedad/845354-mas-de-16-mil-afectados-dejan-lluvias-enlambayeque

17. World Health Organization. Water Quality Monitoring - A Practical Guide to the Design and Implementation of Freshwater. Geneva: WHO; 1996.

\section{Figures}




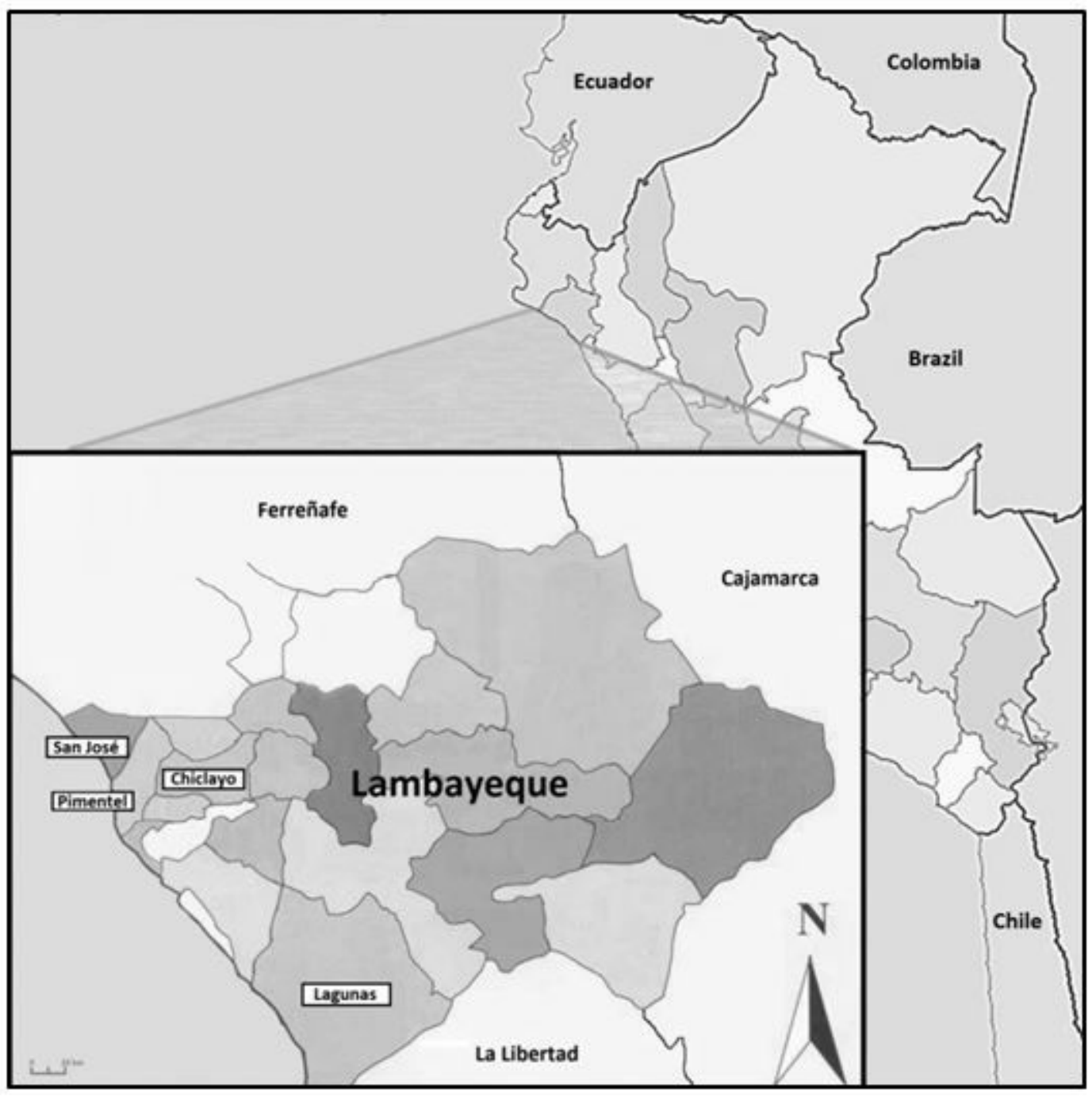

Figure 1

Geographic distribution of the districts evaluated in the Lambayeque region, Peru. 

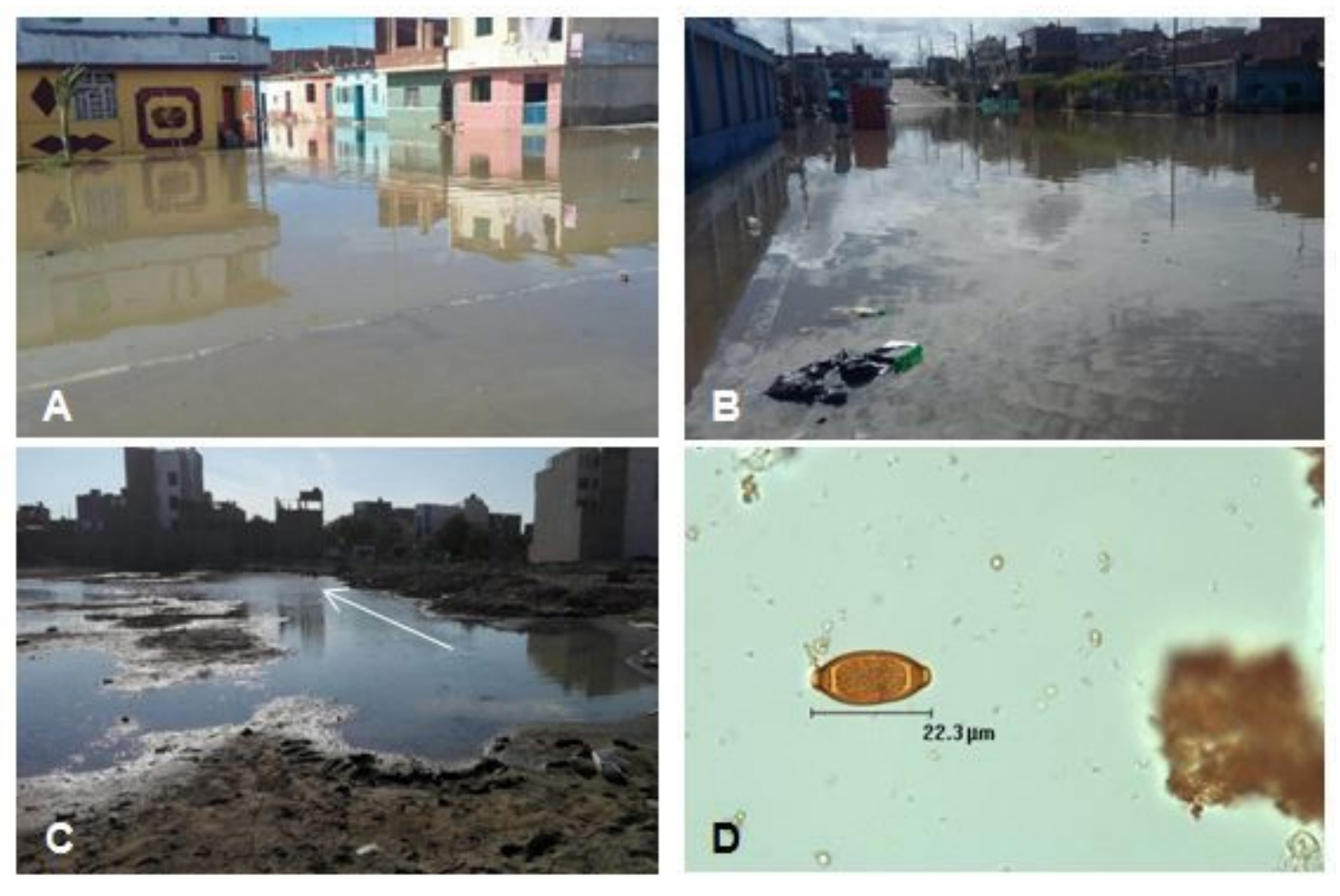

\section{Figure 2}

Typical views of the district areas evaluated in Lambayeque, Peru, and the parasitological finds in Pimentel district. A. San Jose district under stagnant water, B. water stagnation conditions for two weeks in Chiclayo downtown near one of the health centers (left), C. Many of the streets of the Pimentel district are unpaved and the heavy rains and floods caused by El Niño-costero phenomenon resulted in stagnation of water on stilts. Even in this image you can see a group of children swimming in these waters (white narrow). D. the nematode Trichuris trichiura (40x) found in the samples of Pimentel district. 